\title{
Evolution observation of coronal and sagittal spinal curvatures in school children with non-invasive, non- radiating methods: Scoliometer and Debrunner Kyphometer
}

\author{
Panagiotis Korovessis, Vasileios Vitsas, Vasileios Syrimpeis* and Vasileios Tsekouras \\ Orthopaedic Department, General Hospital of Patras, Patras, Greece
}

\begin{abstract}
Study design: A cross-sectional study

Summary and background data: Both Scoliometer and Debrunner's Kyphometer are validated and widely accepted as surface non-invasive, non-radiating measurement instruments for school screening programs for detection and measurement of scoliosis, thoracic kyphosis and lumbar lordosis.

Objectives of the study: The authors have questioned if the prevalence of scoliosis and its distribution among gender and spinal levels has changed in the last 20 years; and if the additional measurement of sagittal spinal curvatures is of great importance just like the scoliosis is.

Methods: This cross-sectional observational study was conducted in 2016 in a randomly selected school population in a metropolitan town in the south-western Europe. In 897 adolescents, aged 12-14 years the authors measured both coronal and sagittal spinal curvatures using the scoliometer to measure scoliosis and the Debrunner kyphometer to measure thoracic kyphosis and lumbar lordosis. Previously validated mathematical formulae were used to estimate with high accuracy the predicted Cobb angle. Leg discrepancy was evaluated and correlated with scoliosis.

Results: The reliability of measurement with the Debrunner's kyphometer and Scoliometer was high. There were 124 (13.8\%) subjects with scoliosis curve-ATR/ value of $\geq 2^{\circ}$. The $99.94 \%$ were single-level curves, and $0.06 \%$ double curves. The right thoracic curve was the most frequent (49\%), followed by the right thoracolumbar (19\%); left lumbar (12\%); left thoracic (8\%); right lumbar $(6 \%)$ and left thoracolumbar $(6 \%)$. Girls showed higher prevalence than boys in right thoracic $(\mathrm{P}=0.009)$ and right thoracolumbar $(\mathrm{P}=0.014)$ curves. In contrary, in 53 subjects ( 40 girls, 13 boys) with $\mathrm{ATR} \geq 5^{\circ}$ : no significant gender-related difference and right to left side localization of scoliosis was disclosed; there were 4 (7.5\%) individuals with right thoracic ATR: 9 (17\%) with left thoracic; 13 (25\%) right thoracolumbar; 4 (7.5\%) left thoracolumbar; 2 (4\%) right lumbar and 10 (19\%) left lumbar.

There was a statistically significant positive correlation between right lumbar ATR and ipsilateral leg shortening $(\mathrm{P}=0.000)$. These findings are within previous similar school screening reports in this country in the last 20 years.

Thoracic kyphosis increases linearly with lumbar lordosis. Boys showed greater thoracic kyphosis and less lumbar lordosis than girls. Fourteen (0.15\%) individuals with Kyphometer values $\geq 55^{\circ}$ were sent for radiological examination. Fifty three (5.9\%) subjects (3.2\% boys and $8.2 \%$ girls) with ATR $\geq 5^{\circ}$ were sent for radiological examination.

Conclusions: The authors recommend to physicians engaged in scoliosis screening programs to use the Debrunner Kyphometer and Scoliometer together with the mathematic formulas for accurate Cobb angle measurement. We believe that this method will reduce the cost of school screening programs, the over diagnosis, and the unnecessary exposure to radiation of young population in the future.
\end{abstract}

\section{Introduction}

In the past, early detection of coronal deformities (scoliosis) was the main target of school screening programs. Evaluation of sagittal alignment has received in the last decade an increasing importance as important is the evaluation of the coronal alignment. However, only few studies have included sagittal alignment into the school screening programs.

Early detection of both coronal and sagittal alignment in young children in the period of quick growth of the spine is of major importance for evaluation and appropriate treatment of the spinal deformities.
The exact value of the degree of scoliosis, thoracic kyphosis and lumbar lordosis is traditionally based on the standing lateral radiograph of the spine and Cobb angle magnitude. Spinal radiograms, although

${ }^{\star}$ Correspondence to: Vasileios Syrimpeis, Orthopaedic Surgeon, Orthopaedic Department, General Hospital of Patras, Patras, Greece, Tel: 306976638786, E-mail: vsyrimpeis@gmail.com

Key words: Debrunner's kyphometer, scoliometer, scoliosis, kyphosis prediction, school screening

Received: February 04, 2019; Accepted: March 01, 2019; Published: March 04, 2019 
Korovessis P (2019) Evolution observation of coronal and sagittal spinal curvatures in school children with non-invasive, non-radiating methods: Scoliometer and Debrunner Kyphometer

invaluable in diagnosis and follow-up evaluation, carry the risk of serious exposure of young adolescents to ionizing radiation.

The advantages of a non radiographic measurement are based in the examination repeatability, low cost and lack of side effects. The ideal instrument for a quick clinical use should be effective, precise, easy to use, and reasonably priced.

Scoliometer is the most commonly used instrument to quick measuring of scoliosis [1] and Kyphometer to evaluating thoracic kyphosis and lumbar lordosis [2-4]. Other instruments used for non-radiographic measurement of kyphosis and lumbar lordosis were the spinal pantograph [5,6], Myrin's modified inclinometer [7], and Acrometer [8], however, the overall agreement between these noninvasive methods and radiography was not satisfactory.

There are previous studies that supported non-invasive methods in combination with simple mathematic formulae for the estimation of both coronal [1] and sagittal [2] spinal curvatures during school screenings to reduce the referral rate of young boys and girls for radiological evaluation of spinal deformities.

Limb length discrepancy is commonly implicated in school screening examination for scoliosis because of a physiological shortening of one leg $(1-2 \mathrm{~cm})$ is associated with a contralateral hump on the back in forward flexion. It has been reported that the shortening of one lower limb is associated with contralateral hump on the back not only at the lumbar region but also in the thoracic area [9]. To determine spinal coronal and sagittal profiles in asymptomatic children, we conducted a cross-sectional study in school children using non-radiating methods (Scoliometer, kyphometer) to estimate scoliosis, thoracic kyphosis and lumbar lordosis. Limb length discrepancy was also evaluated and correlated with coronal curvature.

The authors of this study have questioned: 1) whether the prevalence of scoliosis, as it is measured in school screening in this country, has changed in the last 20 years and 2) whether the measurement of both coronal and sagittal curvatures with noninvasive methods is essential for the diagnosis of spinal deformities in a west-southern Mediterranean Metropolitan city.

\section{Materials and methods}

\section{Subjects}

This was a cross-sectional school screening program carried out in schools who accepted to participate in a Metropolitan town in southwestern town of Europe with a population of 350,000 citizens from October 2013 to April 2014. There were examined 906 students in the ages of $12-14(12 y=G 1 ; 13 y=G 2$ and $14 y=G 3)$ from 13 randomly selected secondary schools that agreed to participate in a Mediterranean country. Approval was taken from the Ethical Committee of this Institution before this screening. Eleven $(1,2 \%)$ subjects ( 7 female, 3 male) were excluded from the analysis because they were already under treatment with brace either for scoliosis or thoracic kyphosis. The remaining 896 were included in the analysis.

The inclusion criteria for this study were: (1) written consensus of the protocol by the adolescents and their parents; (2) ethical approval from the authors' institution committee; (3) non reported radiologically evident scoliosis or thoracic kyphosis under brace treatment and or scoliosis/kyphosis surgically treated; (4) no active spine disease (disc disease, infection etc); and (5) no spinal trauma. Following that, every student was asked to stand with extended knees and hips with the arms close to the body, to perform the following measurements: 1) thoracic kyphosis, 2) lumbar lordosis with the kyphometer, 3) Axial Trunk Rotation (ATR) (scoliosis) and 4) leg length difference and side of shortening.

Data were collected in the morning session in all three classes of the selected local high schools since there are no schools in the afternoon in this country. Following that, each student was asked to stand with extended knees and hips with the arms close to the body, to perform the following measurements: 1) thoracic kyphosis and 2) lumbar lordosis with the Debrunner's Kyphometer.

\section{Measuring instruments and methods}

Measurement of thoracic kyphosis and lumbar lordosis: The thoracic kyphosis and lumbar lordosis were measured in a standing position [2,4], from a point between the spinous processes of the $2^{\text {nd }}$ to $3^{\text {rd }}$ thoracic vertebra and from a second point between the spinous processes of $\mathrm{T}_{11}$ and $\mathrm{T}_{12}$ and sacrum. These points of measurement were located by palpation [10] because palpation methods of identifying vertebra levels are remarkably (97\%) accurate [5]. The authors used two additional landmarks for location of the $\mathrm{T}_{1}$ and $\mathrm{T}_{12}$ vertebrae: the spinal process of the first thoracic vertebra was localized as follows: by palpation of the spinal process of the $6^{\text {th }}$ cervical vertebra that is the most mobile cervical vertebra during flexion and extension of the neck we find the spinal process of the $\mathrm{T}_{1}$-vertebra. The $\mathrm{T}_{12}$-vertebra was localized by palpating the $12^{\text {th }}$ rib and following its course upwards to the spine. The degrees of kyphosis were directly read from the scale of the kyphometer. The lordosis was calculated from the T12 vertebra to $\mathrm{S} 1$ that is localized from the palpation of the prominent facets of $\mathrm{L} 5 / \mathrm{S} 1$ bilaterally.

The coefficient of variation for lumbar lordosis measurements with the kyphometer has been shown to be very low (7.4\%) [6].

Debrunner's Kyphometer (Protek, AG, Bern, Switzerland) has a protractor with a $1^{\circ}$ scale at the end of two double, parallel arms, which are connected to two blocks, large enough to span two spine processes (Figure 1). The indicated by the name "Kyphometer" was originally designed [11] to measure kyphosis of up to $52^{\circ}$. This limitation of the measurement is a problem when measuring lordosis and lumbar extension which often exceeds $52^{\circ}$. After the modification of the cutout in the frame, performed by Ohlen et al. [4] in 1989, the range of measurement of the kyphometer has been increased to $70^{\circ}$. The modified Debrunner's Kyphometer (Figure 1) by Ohlen et al. [4] was used in this study.

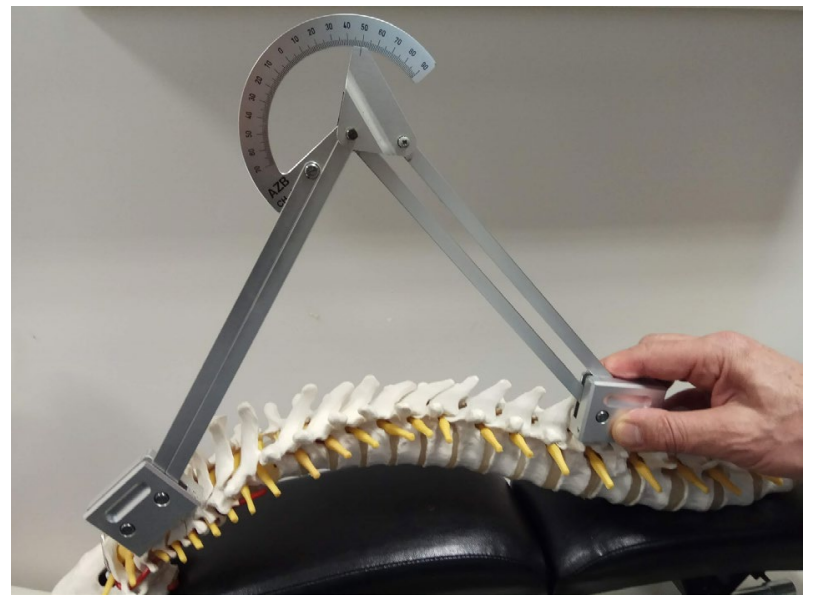

Figure 1. The debrunner kyphometer 
Korovessis P (2019) Evolution observation of coronal and sagittal spinal curvatures in school children with non-invasive, non-radiating methods: Scoliometer and Debrunner Kyphometer

The authors are aware that the measurement of sagittal spinal curvatures (thoracic kyphosis and lumbar lordosis) with the use of the kyphometer represents back surface contour analysis and the obtained values do not represent the real roentgenographic curve values. The kyphometer has shown a reliability of 84 to $98 \%$ in measuring thoracic kyphosis and lumbar lordosis [9,4,12-16].

Measurement of scoliosis: The measurement of scoliosis-axial trunk rotation (ATR) using the Scoliometer is a noninvasive, radiation free method of screening for scoliosis in school screening programs and practice. It can be easily implemented, and it had been proven to have good correlation with radiological analysis $(\mathrm{r}=0.7, \mathrm{p}<0.05)$ and very good intra-rater reliability $[1,17,18]$.

The Scoliometer (Orthopedic Systems Inc., Hayward, CA, USA) is an inclinometer that measures the ATR in the forward bending position (Adam's test). If a rotational deformity of the back is noted, at any spinal level, the scoliometer is gently placed along the thoracic and lumbar spine or both, perpendicular to the long axis of the body and the largest (several measurements at different levels were made) ATR value per spinal level or levels is read and recorded.

\section{Statistical methods}

Data were analyzed using SPSS (v.18, SPSS, Inc., Chicago, IL, USA). Continuous data were reported as mean $\pm \mathrm{SD}$ and categorical data were reported as frequencies and percentages.

Levene's test of homogeneity of variables was used in all tests.

One-way ANOVA was used to test for between-group differences for continuous variables, with Bonferroni multiple-comparison test if the global tests indicated significance. Two-sided p-values $<0.05$ were considered statistically significant.

Simple Linear Regression Analysis (SLRA) was used to correlate two variables.

\section{Results}

897 individuals, 409 (45.5\%) boys and 488(54.5\%) girls were included in the analysis, after the exclusion of the individuals who met the exclusion criteria (Table 1).

There were 323 (36\%) individuals in the 12-year group; 278 (31\%) in the 13-year old group and 295 (33\%) in the 14-year old group.

The inter observer agreement (kappa) in the clinical measurement of coronal curvatures was 0.68 ; and the same for sagittal curvatures, the kappas for lumbar lordosis was 0.67 , and 0.87 for thoracic kyphosis.

In 897 individuals who were examined with the Kyphometer, the average \pm SD thoracic kyphosis was $44 \pm 8^{\circ}$, range $23-56^{\circ}$ and the lumbar lordosis was $39 \pm 7^{\circ}$, range $20-54^{\circ}$.

Male adolescents showed an average \pm SD thoracic kyphosis of $45 \pm 8^{\circ}$, which was greater than that of their female counterparts: $43 \pm 8^{\circ}$ (ANOVA, $\mathrm{P}=0.000$ ), (Table 1).

Girls showed a lordosis of $40 \pm 7^{\circ}$, which was greater than that of boys $38 \pm 7^{\circ}$ (ANOVA, $\mathrm{P}=0.000$ ), (Table 1 ).

There was a significant difference of the kyphosis magnitude between the age groups (ANOVA, $\mathrm{P}=0.001$ ). Bonferroni post hoc test showed a significant difference of the kyphosis angle only between the groups of 12 and 14 years $(\mathrm{P}=0.000)$, (Table 2$)$.
Table 1. Sagittal curvatures presented per gender

\begin{tabular}{|c|c|c|c|c|}
\hline Gender & Number & $\mathbf{( \% )}$ & $\begin{array}{c}\text { Thoracic } \\
\text { Kyphosis }^{*, * *}\end{array}$ & $\begin{array}{c}\text { Lumbar } \\
\text { Lordosis }^{*, * *}\end{array}$ \\
\hline Boys & 409 & 45.5 & $\begin{array}{c}45 \pm 8^{\circ}(\mathrm{CI}: \\
45-46)\end{array}$ & $\begin{array}{c}38 \pm 7^{\circ}(\mathrm{CI}: \\
37-38)\end{array}$ \\
\hline \multirow{2}{*}{ Girls } & 488 & 54.5 & $\begin{array}{c}43 \pm 8^{\circ}(\mathrm{CI}: \\
43-44)\end{array}$ & $\begin{array}{c}40 \pm 7^{\circ}(\mathrm{CI}: \\
39-40)\end{array}$ \\
\hline \multicolumn{2}{|c|}{ P-value (ANOVA) } \\
\hline \multicolumn{2}{|c|}{} & & $\mathbf{F}=\mathbf{1 5}, \mathbf{P}=\mathbf{0 . 0 0 0}$ & $\mathbf{F}=\mathbf{1 9 . 6 ,} \mathbf{P}=\mathbf{0 . 0 0 0}$ \\
\hline
\end{tabular}

"Debrunner Kyphometer Degrees

** Levene's test of homogenity of variances Kyphosis $\mathrm{P}=0.358$ and Lordosis $\mathrm{P}=0.139$

${ }^{* * *}$ ANOVA P-value for differences between genders

$\mathrm{CI}=95 \%$ Confidence interval

Table 2. Sagittal curvatures presented per age group

\begin{tabular}{|c|c|c|c|c|}
\hline Age group & $\mathrm{N}$ & $\mathbf{( \% )}$ & $\begin{array}{c}\text { Thoracic } \\
\text { Kyphosis }^{*}\end{array}$ & $\begin{array}{c}\text { Lumbar } \\
\text { Lordosis }^{*}\end{array}$ \\
\hline 12 years & 323 & 36 & $44 \pm 8$ (CI: 43-45) & $37 \pm 7$ (CI: 38-40) \\
\hline 13 years & 278 & 31 & $45 \pm 7$ (CI: 44-46) & $39 \pm 7$ (CI: 38-40) \\
\hline 14 years & 295 & 33 & $46 \pm 7$ (CI: 45-47) & $39 \pm 7$ (CI: $38-40)$ \\
\hline \multicolumn{2}{|c|}{ P-value (ANOVA) $^{* * *}$} & & F=7.53, P=0.001 & $\begin{array}{c}\text { F=0.502, } \\
\mathrm{P}=0.606\end{array}$ \\
\hline \multicolumn{2}{|c|}{ Post hoc Bonferoni test ${ }^{+}$} & $\mathrm{P}=0.000$ & $\mathrm{P}=1$ \\
\hline
\end{tabular}

"Debrunner Kyphometer Degrees

"Levene's test of homogenity of variances Kyphosis $\mathrm{P}=0.521$ and Lordosis $\mathrm{P}=0.683$

${ }^{* * *}$ ANOVA P-value for differences between age groups

${ }^{+} 12$ years vs 14 years age groups

$\mathrm{CI}=95 \%$ Confidence Interval

No difference between age groups were shown in the lordosis (ANOVA, $\mathrm{P}=0.606$ ), (Table 2). Bonferroni post hoc test showed no significant differences in the lordosis values as it was measured with the Debrunner's Kyphometer ( $\mathrm{P}=1)$, (Table 2).

Scoliosis with ATR $>2^{\circ}$, measured by the Scoliometer, was shown in 124 (13.8\%) from 897 individuals; while in $5(0.06 \%)$ individuals the ATR was measured in two different spinal regions (double curves). In the 124 individuals with ATR $>2^{\circ}$, the relative prevalence of right-sided thoracic scoliosis was $49 \%$; the right thoracolumbar was $19 \%$; the left lumbar was $12 \%$; the left thoracic was $8 \%$; the right lumbar was $6 \%$ and the thoracolumbar left was $6 \%$ (Table 3 ).

When comparing ATR $>2^{\circ}$ per spinal level between the two genders (Table 4) there was a significantly higher thoracic right (ANOVA, $\mathrm{P}=0.009$ ) and right thoracolumbar (ANOVA, $\mathrm{P}=0.014$ ) ATR value in girls, while no difference was shown in the other spinal levels.

The ATR value between different spinal levels was not correlated with age (post hoc test) differences between age groups (Table 5).

ATR localization per age group is shown in Table 6.

Fifty-three subjects (40 girls and 13 boys) showed ATR $>5^{\circ}$. No significant difference between the two genders and right to left side localization of scoliosis were disclosed (Table 7). In particularly, there were 4 (7.5\%) individuals with right thoracic ATR; 9 (17\%) with left thoracic ATR; 13 (25\%) with right thoracolumbar ATR; 4 (7.5\%) with left thoracolumbar ATR; 2 (4\%) with right lumbar and 10 (19\%) with left lumbar ATR.

There was a statistically significant positive correlation between right lumbar ATR and ipsilateral leg shortening (Pearson $\mathrm{R}=0.117$, $\mathrm{P}=0.000$ ), (Table 8).

Table 8 shows scoliosis (ATR) and kyphosis/lordosis (Kyphometer) average \pm SD values versus predicted scoliosis and kyphosis/lordosis Cobb angles respectively, with the application of previously published validated mathematical formulas $[1,2]$. 
Korovessis P (2019) Evolution observation of coronal and sagittal spinal curvatures in school children with non-invasive, non-radiating methods: Scoliometer and Debrunner Kyphometer

Table 3. Scoliometer-Axial Trunk Rotation $\left(A T R>2^{\circ}\right.$ ) distribution per spinal level in 896 individuals

\begin{tabular}{|c|c|c|c|c|c|c|c|c|}
\hline $\begin{array}{l}\text { Axial Trunk } \\
\text { Rotation }\end{array}$ & $\mathbf{N}$ & $(\%)$ & $\operatorname{Mean} \pm$ SD & Minimum & Maximum & Variance & $\begin{array}{l}\text { Levene's } \\
\text { P-value }^{*}\end{array}$ & $\begin{array}{l}\text { ANOVA } \\
\text { P-value }^{* * *}\end{array}$ \\
\hline Thoracic Right & 61 & (49) & $4.4 \pm 8.2$ & 2 & 10 & 4.35 & 0.786 & 0.639 \\
\hline Thoracic Left & 10 & $(8)$ & $4.8 \pm 1.5$ & 3 & 7 & 2.2 & 0.193 & 0.637 \\
\hline Thoracolumbar Right & 24 & (19) & $6.1 \pm 2.3$ & 2 & 9 & 5.2 & 0.178 & 0.079 \\
\hline Thoracolumbar Left & 7 & $(6)$ & $6.57 \pm 2$ & 4 & 10 & 4.3 & 0.653 & 0.081 \\
\hline Lumbar Right & 8 & (6) & $5.5 \pm 2.4$ & 3 & 8 & 5.7 & 0.213 & 0.171 \\
\hline Lumbar Left & 15 & $(12)$ & $6.08 \pm 2$ & 3 & 10 & 4.4 & 0.258 & 0.473 \\
\hline Total & 125 & $(100)$ & & & & & & \\
\hline
\end{tabular}

"Levene's test of homogeneity between variables

**ANOVA between groups

Table 4. Axial Trunk Rotation distribution per spinal level and gender in 896 individuals

\begin{tabular}{|c|c|c|c|c|c|}
\hline Axial Trunk Rotation & Gender & Mean \pm SD & $\begin{array}{l}\text { Levene's test } \\
\text { P-value }\end{array}$ & ANOVA F-value ${ }^{* *}$ & $\begin{array}{l}\text { ANOVA } \\
\text { P-value }\end{array}$ \\
\hline \multirow{2}{*}{ Thoracic Right } & Female & $0.088 \pm 0.28$ & \multirow{2}{*}{0.000} & \multirow{2}{*}{6.8} & \multirow{2}{*}{0.009} \\
\hline & Male & $0.044 \pm 0.20$ & & & \\
\hline \multirow{2}{*}{ Thoracic Left } & Female & $0.01 \pm 0.11$ & \multirow{2}{*}{0.140} & \multirow{2}{*}{0.545} & \multirow{2}{*}{0.461} \\
\hline & Male & $0.01 \pm 0.086$ & & & \\
\hline \multirow{2}{*}{ Thoraco-lumbar Right } & Female & $0.038 \pm 0.19$ & \multirow{2}{*}{0.000} & \multirow{2}{*}{6.095} & \multirow{2}{*}{0.014} \\
\hline & Male & $0.012 \pm 0.11$ & & & \\
\hline \multirow{2}{*}{ Thoraco-lumbar Left } & Female & $0.01 \pm 0.078$ & \multirow{2}{*}{0.216} & \multirow{2}{*}{0.383} & \multirow{2}{*}{0.536} \\
\hline & Male & $0.01 \pm 0.099$ & & & \\
\hline \multirow{2}{*}{ Lumbar Right } & Female & $0.01 \pm 0.09$ & \multirow{2}{*}{0.611} & \multirow{2}{*}{0.065} & \multirow{2}{*}{0.799} \\
\hline & Male & $0.01 \pm 0.099$ & & & \\
\hline \multirow{2}{*}{ Lumbar Left } & Female & $0.01 \pm 0.11$ & \multirow{2}{*}{0.023} & \multirow{2}{*}{1.268} & \multirow{2}{*}{0.257} \\
\hline & Male & $0.02 \pm 0.14$ & & & \\
\hline
\end{tabular}

" Levene's test of homogeneity between variables

*ANOVA between gender groups

Table 5. Multiple comparisons (Post hoc tests) of Axial Trunk Rotation (ATR) per spinal level versus age group (G1, G2 and G3) in 896 individuals, G1=12years age group, G2=13years age group, G3=14years age group

\begin{tabular}{|c|c|c|c|c|}
\hline ATR & $\begin{array}{c}\text { Age groups comparisons } \\
\text { G1 vs G2\&G3 }\end{array}$ & $\begin{array}{c}\text { Age groups } \\
\text { comparisons } \\
\text { G2 vs G1\&G3 }\end{array}$ & $\begin{array}{c}\text { ANOVA } \\
\text { (P-value) } \\
\text { between groups }\end{array}$ & $\begin{array}{c}\text { Age groups comparisons } \\
\text { G3 vs G1\&G2 }\end{array}$ \\
\hline Thoracic Right & $0.617-0.871$ & $0.617-0.954$ & $0.871-0.954$ \\
\hline Thoracic Left & $0.851-0.661$ & $0.851-0.982$ & $0.661-0.982$ \\
\hline Thoraco-lumbar Right & $0.068-0.294$ & $0.068-0.453$ & $0.294-0.453$ \\
\hline Thoraco-lumbar Left & $* *$ & 0.673 & \\
\hline Lumbar Right & $*$ & $*$ & 0.079 \\
\hline Lumbar Left & $0.965-0.682$ & $0.965-0.474$ & 0.171 \\
\hline
\end{tabular}

"Post hoc tests not performed for Scoliometer measurements for Thoraco-lumbar Left and Lumbar Right, because one group had only one case. For this test, at least two cases are required.

Table 6. Axial Trunk Rotation per age group and localization

\begin{tabular}{|c|c|c|c|c|c|c|}
\hline \multirow{2}{*}{ Age group } & Thoracic Right & Thoracic Left & Thoraco-lumbar Right & Thoraco-lumbar Left & Lumbar Right & Lumbar Left \\
\hline & $\mathrm{N}(\%)$ & $\mathrm{N}(\%)$ & $\mathrm{N}(\%)$ & $\mathrm{N}(\%)$ & $\mathrm{N}(\%)$ & $\mathrm{N}(\%)$ \\
\hline $12 y$ & $20(53)$ & $5(13)$ & $4(9)$ & $4(9)$ & $2(6)$ & $4(9)$ \\
\hline $13 y$ & $20(59)$ & $2(7.4)$ & $4(11)$ & $1(3.7)$ & $1(3.7)$ & $4(14.8)$ \\
\hline $14 y$ & $11(35)$ & $5(15.4)$ & $5(15.4)$ & $4(11.5)$ & $1(3.8)$ & $6(19.2)$ \\
\hline Total & 51 & 12 & 12 & 9 & 5 & 15 \\
\hline
\end{tabular}

Table 7. Scoliometer-Axial Trunk Rotation $\geq 5$ degrees presented per gender and spinal level localization in 53 subjects

\begin{tabular}{|c|c|c|c|c|c|c|c|}
\hline & $\begin{array}{c}\text { Thoracic } \\
\text { Right }\end{array}$ & $\begin{array}{c}\text { Thoracic } \\
\text { Left }\end{array}$ & $\begin{array}{c}\text { Thoraco-lumbar } \\
\text { Right }\end{array}$ & $\begin{array}{c}\text { Thoraco-lumbar } \\
\text { Left }\end{array}$ & $\begin{array}{c}\text { Lumbar } \\
\text { Right }\end{array}$ & $\begin{array}{c}\text { Lumbar } \\
\text { Left }\end{array}$ & \\
\hline & $N$ mean $\pm S D^{+}$ & $N$ & $N$ mean $\pm S D^{+}$ & $N$ mean $\pm S D^{+}$ & $N$ & N mean $\pm S D^{+}$ & Total \\
\hline Girls & $167 \pm 1^{\circ}$ & 4 & $107 \pm 1^{\circ}$ & $38 \pm 2^{\circ}$ & 1 & $67 \pm 2^{\circ}$ & 40 \\
\hline Boys & $28 \pm 4^{\circ}$ & 1 & $36 \pm 1^{\circ}$ & $27 \pm 2^{\circ}$ & 1 & $46 \pm 1^{\circ}$ & 13 \\
\hline Total & 18 & 5 & 13 & 5 & 2 & 10 & 53 \\
\hline $\begin{array}{l}\text { ANOVA } \\
P \text {-value between genders }\end{array}$ & 0.553 & 1 & 0.280 & 0.444 & * & 0.355 & \\
\hline $\begin{array}{l}\text { Levene's } \\
\text { homogeneity P-value }\end{array}$ & 0.034 & * & 0.515 & 0.724 & * & 0.361 & \\
\hline
\end{tabular}

"Groups with only one case are ignored in computing the Levene's test of homogeneity

+ Angle degrees 
Korovessis P (2019) Evolution observation of coronal and sagittal spinal curvatures in school children with non-invasive, non-radiating methods: Scoliometer and Debrunner Kyphometer

Table 8. Scoliosis and Thoracic Kyphosis measured by Scoliometer and Kyphometer respectively versus predicted Cobb angle

\begin{tabular}{|c|c|c|c|}
\hline & Measured angle $^{*}$ & Predicted angle $^{*}$ & Instrument \\
\hline Thoracic Kyphosis & $44 \pm 8$ & $42 \pm 15$ & Kyphometer $^{+}$ \\
\hline Thoracic Right & $4 \pm 2$ & $13 \pm 9$ & Scoliometer $^{\#}$ \\
\hline Thoracic Left & $5 \pm 1.5$ & $14 \pm 9$ & Scoliometer \\
\hline Thoraco-lumbar Right & $5 \pm 2$ & $14 \pm 8$ & Scoliometer \\
\hline Thoraco-lumbar Left & $7 \pm 2$ & $18 \pm 9$ & Scoliometer \\
\hline Lumbar Right & $4 \pm 2$ & $13 \pm 10$ & Scoliometer \\
\hline Lumbar Left & $6 \pm 2$ & $17 \pm 10$ & Scoliometer \\
\hline
\end{tabular}

"Cobb angle degrees (average \pm SD)

${ }^{+}$Korovessis et al. Journal of Spinal Disorders

Techniques, 2001

\#Korovessis et al. Spine, 1996

Thoracic kyphosis increases as the lumbar lordosis angle increases (SLRA R=0.233, $\mathrm{P}=0.000$ ).

There was a negative statistically significant correlation between lumbar lordosis and male gender (Pearson $\mathrm{R}=-0.145, \mathrm{P}=0.000$ ). There was a statistically significant positive correlation between thoracic kyphosis and female gender (SLRA $\mathrm{R}=0.08, \mathrm{P}=0.000$ ).

No correlation was found between thoracic scoliosis-ATR $\geq 2^{\circ}$ and thoracic kyphosis (ANOVA, $\mathrm{P}=0.139$ ) nor with thoracic scoliosis$\mathrm{ATR} \geq 5^{\circ}$ and thoracic kyphosis (ANOVA, $\mathrm{P}=0.976$ ).

In the present study, in the age range 12 to 14 years, the referral rate for scoliosis with ART $\geq 5^{\circ}$ was $5.9 \%$. Fifty three from the 897 examined subjects were sent for roentgenographic examination. In particular, the referral rate for boys was 3.2\% (13 from 409 subjects), and $8.2 \%$ for girls (40 from 488 subjects).

With ATR cut off value in $5^{\circ}$ the predicted Cobb value with the use of scoliometer plus mathematical formula [1] was for thoracic/thoracolumbar scoliosis $14 \pm 5.6^{\circ}$ and for lumbar $15 \pm 5.8^{\circ}$ roentgenographic Cobb angles close to those that may progress and may require bracing.

Fourteen $(0.15 \%)$ individuals with Kyphometer values $255^{\circ}$ were sent for radiological examination, because according to a previously validated mathematic formula [2] the predicted radiological Cobb angle is $>50^{\circ}$.

For individuals with $\mathrm{ATR} \geq 5^{\circ}$ and Kyphometer values $\geq 55^{\circ}$ a confidential letter was handed via the director of the School for the parents to visit their Orthopaedic for radiological examination. There was no feedback regarding the roentgenographic values for scoliosis and Kyphosis.

\section{Discussion}

In this cross-sectional study, 897 asymptomatic students in the age range 12 to 14 years were randomly recruited from eleven secondary schools in a metropolitan town in a west-southern Mediterranean country for simultaneous coronal and sagittal spinal curvature measurements, using non-radiating methods (Scoliometer and Debrunner's Kyphometer) and validated mathematic formulas for prediction of Scoliosis, Kyphosis, and Lordosis [1,2]. The authors' aim was to record current spinal deformities and to compare them with those recorded 20 years before in the same country.

Sagittal spinal curvatures only exceptionally were examined in the past school screening programs since the screenings were considered mostly for scoliosis [16]. In this school screening program the authors have measured not only coronal but also sagittal spinal curves using surface instruments and was found that this combined measurement is effective, it takes just a little more time than the scoliometer solely and is costless.

In this study, the inter observer agreement (kappas) for the clinical measurement of coronal curvatures with the Scoliometer and for sagittal curvatures, measured with the Debrunner's Kyphometer were high, within the previously reported limits $[4,11,12,16]$.

\section{Scoliosis}

There were $124(13.8 \%)$ subjects with ATR/curve value of $\geq 2^{\circ}$. The vast majority $(99.94 \%)$ were single-level curves, while only 5 $(0.06 \%)$ adolescents showed double curves. The right thoracic curve was the most frequent (49\%), followed by the right thoracolumbar (19\%); left lumbar (12\%); left thoracic (8\%); right lumbar (6\%) and left thoracolumbar $(6 \%)$ respectively. In our study, in accordance to previous ones, girls showed higher prevalence than boys in right thoracic $(\mathrm{P}=0.009)$ and right thoracolumbar $(\mathrm{P}=0.014)$ curves. These findings are within previous similar school screening reports in this country [1,19-21].

There are four previously published peer review studies reporting on school screening for scoliosis with Scoliometer in the same country and race as the present study, but in different age groups [1,19-21].

Korovessis et al. in an observational study in 1996 [1] screened 10,109 schoolchildren aged 8-16 years old and reported radiologically $66.5 \%$ thoracic; $27.5 \%$ S-shaped; and $6 \%$ lumbar scoliosis curves. In this screening, $5.7 \%$ were referred for roentgenographic examination.

One year later in 1997 the reported results of school screening for scoliosis in 82,901 school children aged 9-14 years [19] were: $6.9 \%$ of the examined subjects had clinical signs of scoliosis and of these, $5 \%$ were referred for roentgenographic examination. They did not report on surface measurement results. The roentgenographic prevalence of scoliosis $\geq 10^{\circ}$ Cobb was $1.7 \%$. Thoracolumbar curves were the most common type of curve identified, followed by lumbar curves; specifically, in children who had a curve of $\geq 10^{\circ}: 34.3 \%$ had a thoracolumbar curve; $33.1 \%$ had a lumbar curve; $18.2 \%$ had a thoracic curve, and $14.4 \%$ had a double curve, respectively.

Sapkas et al. [20] in a prospective study of 291 children and adolescents with idiopathic scoliosis found a statistically significant correlation between thoracic, thoracolumbar, and lumbar scoliometer values (ATR) and the thoracic, thoracolumbar and lumbar Cobb angles, respectively.

Grivas et al. [21] analyzing the reliability of scoliometer measurements, taken in school screening programs in this country, reported maximal variability at the lumbar and minimal variability at the thoracic spine.

In the 2013 school screening performed by us, the findings had some similarities with those previously reported by Soucacos et al. [19]: our referral rate in the present study with ATR cut off to be $\geq 5^{\circ}$ was $5.9 \%$ for age range 12-14 years, while in the Soucacos et al. study [19] with cut off $A T R \geq 5$ the referral rate was $5 \%$, but in a wider age range (9-14 years old).

Differences between our findings and those in previous study in this country [19] were the increased prevalence of right-sided thoracic scoliosis (49\%); the right thoracolumbar (19\%); the left lumbar (12\%); the left thoracic (8\%); the right lumbar $(6 \%)$ and the thoracolumbar left (6\%). These differences should be due to the different methods of ATR measurement and the different age groups in the two studies. 
Korovessis P (2019) Evolution observation of coronal and sagittal spinal curvatures in school children with non-invasive, non-radiating methods: Scoliometer and Debrunner Kyphometer

Grivas et al. [21] measured with the Scoliometer the ATR of 2,071 children and adolescents aged 5 to 18 years old, from the same country and ethnicity as in our study. Right ATR/scoliosis was the most common.

Although there are several studies supporting the use of the Scoliometer for measurement of ATR, Bunnell [19] raised concerns about the reliability to predict the degree of scoliosis curvature from surface topography in any given patient by any technique. Additionally, it has also been reported that patients with double curves have significantly less trunk deformity in both the transverse and coronal plane than patients with thoracic and thoraco-lumbar curves of similar Cobb size [22].

There is some diversity regarding referral rate for radiological examination of school children, screened with the Scoliometer, ranging from $5^{\circ}$ to $7^{\circ}[23,24]$. With reference rate of $3.4 \%$ in the Lonstein et al. [24] school screening series the prevalence of scoliosis was $1.2 \%$.

In our study, with referral ART $\geq 5^{\circ}$ the referral rate was $5.9 \% ; 3.2 \%$ for boys and $8.2 \%$ for girls. It seems that although the global referral rate remained the same in the last 20 years, the referral rate for girls has increased.

\section{Kyphosis and lordosis}

This study showed an increase of thoracic kyphosis with increasing lumbar lordosis $(\mathrm{P}=0.000)$ in asymptomatic adolescents. Boys had greater thoracic kyphosis than girls $(\mathrm{P}=0.000)$, while girls showed a greater lumbar lordosis than boys $(\mathrm{P}=0.000)$. There was no agerelated difference in the lordosis magnitude $(\mathrm{P}=1)$. Fourteen $(0.15 \%)$ individuals with thoracic Kyphometer values $\geq 55$ degrees were sent for radiological evaluation, because according to a previously validated by us mathematic formula [2] the predicted radiological value should be $>50^{\circ}$ Cobb.

An excellent reliability with the Debrunner's Kyphometer in measuring thoracic kyphosis and lumbar lordosis has been shown [16]. Willner et al. [5,6] compared radiographs with Pantograph measurements for thoracic kyphosis and found good correlation.

D'Osualdo et al. [4] used the Acrometer, a modification of Debrunner's Kyphometer, to measure thoracic kyphosis and reported a good correlation index (0.98) between radiographs and clinical measurements.

In a previous study in this country, [2] the Debrunner's Kyphometer has shown a high predictive value for roentgenographic kyphosis Cobb angle ranged between $24^{\circ}$ to $70^{\circ}$, but more reliable $\leq 50^{\circ}$, equally accurate in male and female individuals. A simple mathematical formula was constructed that shows a difference between predicted and Cobb angle of $2.8^{\circ} \pm 0.9^{\circ}$ on the basis of the observed Kyphometer value [2]. D' Osualdo et al. [8] found a mean \pm SD difference between Cobb angle and Acrometer values of $2.9 \pm 8.8^{\circ}$. In the present study, only 14 $(0.15 \%)$ subjects showed Kyphometer values $\geq 55^{\circ}$, that with the use of the mathematic formula [2] correspond to a Cobb angle of $\geq 50^{\circ}$, as the cut off value for treatment. In this study, the average difference between Kyphosis value measured with the kyphometer and that predicted with the use of the formula [2] was $2^{\circ}$.

In the clinical practice, it is very important that individual observations in spine deformities to be reliable and accurate. For this reason, the position of the individual during the measurement should be stable, simple and repeatable. In this study, we used the well documented method of Stagnara [25] for the erect "relaxed" standing position with the arms rested on the clavicles of the individual during the measurement of sagittal curves.

Surface measurement devices have different degrees of precision and may suffer from different systematic errors. The measurement error can originate from each of the three factors Cox described by Beekan and Hal [26]: the observer, the variable measurement and the apparatus or technique. It is obvious that when performing scoliosis and kyphosislordosis screening, with the use of the Scoliometer and Debrunner's Kyphometer respectively, it is not possible to estimate the approximate degree of the scoliosis and kyphosis Cobb angle in adolescents, without a radiographic examination, because the Scoliometer measures axial trunk rotation and not scoliosis Cobb angle, while the kyphometer measures thoracic kyphosis-lordosis indirectly. However, the measurement of kyphosis with the Kyphometer showed values closer to radiological Cobb angle [2] compared to Scoliometer that measured axial trunk rotation (ATR) and not coronal spinal curvatures [1].

In a previous study, [2] 90 adolescents from the same race, ethnicity and residence with the school children in the present study, were examined with both the kyphometer and roentgenograms and calculated the predicted thoracic kyphosis using a simple mathematical formula and kyphometer value. The predicted kyphosis Cobb angle was $44.7^{\circ} \pm 2.7^{\circ}$, which was at an average of $2.8^{\circ}$ less than the roentgenographic Cobb angle $\left(47 \cdot 5^{\circ} \pm 3 \cdot 5^{\circ}\right)$.

In the school screening programs in the period of 2003-2004 [16], asymptomatic adolescents aged 12 to 18 years from the same race, ethnicity and residence with the school children of our study, were examined for both coronal and sagittal spinal curvatures. The Kyphometer showed similar thoracic kyphosis for boys and girls: $34 \pm 7^{\circ}$ and $35 \pm 6^{\circ}$ respectively that were less in comparison to the more recent school screening program of 2013. In contrary, lumbar lordosis measured with the kyphometer, was for boys $32 \pm 7^{\circ}$, significantly less than in girls $36 \pm 9^{\circ}$ [16]. In the present study, we found a greater lumbar lordosis in girls $\left(40 \pm 7^{\circ}\right)$ than in boys $\left(38 \pm 7^{\circ}\right)$. We speculate that these differences should be due to the different age range of the populations between the two studies.

Stolinski et al. [27] compared the measurements of thoracic kyphosis and lumbar lordosis with photography versus Rippstein plurimeter in 61 healthy children aged 7-9 years. They found no significant difference regarding the measurement of kyphosis, but differences were found for lumbar lordosis. Giglio CA et al. [28] using a pantograph, measured the lordosis and kyphosis in 718 subjects, in the age range of 5 to 20 years and showed a linear kyphosis increase from $25^{\circ}$ at 7 years of age to $38^{\circ}$ at 19 years of age, while lordosis increased linearly from $22^{\circ}$ at 5 years of age to $32^{\circ}$ at 20 years of age. There were no differences between males and females. A similar increase of kyphosis with age was found in our study in the age range 12-14 years.

The angle measured with a scoliometer does not correspond to the Cobb angle measured on a radiograph [29]. Furthermore, the Cobb angle alone cannot explain the whole of the surface deformity [30]. As a consequence, not all patients with radiographic scoliosis have rotation of the trunk and not all patients with trunk rotation have radiographic scoliosis [31].

Grivas [21] found a strong correlation between ATR and the leg length discrepancy, suggesting that the leg length inequality may force the trunk to rotate, so the body will maintain its balance. We found strong correlation between right lumbar ATR and ipsilateral leg shortening, only. 
Korovessis P (2019) Evolution observation of coronal and sagittal spinal curvatures in school children with non-invasive, non-radiating methods: Scoliometer and Debrunner Kyphometer

Leg length asymmetries in normal children are either normalised during growth, or may contribute to the pathogenesis of scoliosis [32].

In our study however we found a statistically significant positive correlation between right lumbar ATR and ipsilateral leg shortening $(\mathrm{P}=0.000)$. Whether this finding could be considered as an indirect sign of correlation between right leg shortening and right-convex scoliosis this statement cannot be extracted from this study. In contrast to previous studies [32], Ingelmark and Lindstrom [33] reported that the causation of scoliosis is very difficult to be established because it may involve a large number of different mechanisms acting singly or in combination. The pattern of scoliosis associated with anisomelia, is usually described as being compensatory, non-structural and nonprogressive. It has also been reported that anisomelia can produce structural changes in the adult spine with time and many of the patients are experiencing back pain $[34,35]$.

Deepak et al. [36] examined 8,966 voluntary school students aged 13-15 years old for scoliosis with the scoliometer. Subjects with ATR $\geq 5^{\circ}$ were examined with radiographs. The radiological assessment referral was $4.2 \%$ for male and $5.0 \%$ for female subjects. In the present study we set as cut off for referring children the ATR $\geq 5^{\circ}$ and the rate for referral was $4.45 \%$, within that previously reported. Others [37] have used in school screening programs a Scoliometer ATR value $>7^{\circ}$ as referral for radiological examination. The prevalence rate of scoliosis was $2.55 \%$. The positive predictive value of Scoliometer was $55.8 \%$, which is adequate to suggest that the school scoliosis screening program did play a role in the early detection of scoliosis. The referral rate at the age of 13 years was $3.5 \%$ for males and $5.0 \%$ for females; and at the age of 14 years it was $4.0 \%$ for males and $4.9 \%$ for females. In our study the global referral rate for roentgenographic examination in the ages of 12 - 14 years with $\mathrm{ART} \geq 5^{\circ}$ was $53 / 897$ (5.9\%) subjects: in particular there were $13 / 409$ male $(3.2 \%)$ and $40 / 488(8.2 \%)$ female, within that previously reported.

Zheng et al. [38] examined 79,122 Chinese school students aged 10-16 years with the scoliometer. Students with an angle of trunk inclination of $\geq 5^{\circ}$ were referred for a whole-spine X-ray. The overall prevalence of adolescent idiopathic scoliosis was estimated as $2.4 \%$. In our study the average referral rate in the ages $12-14$ years for ATR $\geq 5^{\circ}$ was $5.9 \%$.

Girls had a higher prevalence in every age subgroup compared with boys. Mild and moderate curves were the most common types in our study.

The sensitivity and specificity of scoliosis screening depends on the skills of the examiner and on the magnitude of the scoliosis. The use of scoliometer has been shown to increase the sensitivity and the specificity in detecting a Cobb angle of $>20^{\circ}$ [39]. A scoliometer reading of $5^{\circ}$ has been shown to have a sensitivity of $100 \%$, and $47 \%$ specificity for identification of scoliosis, whereas a scoliometer reading of $7^{\circ}$ increases the specificity to $86 \%$ but decreases the sensitivity to $83 \%$ [40].

The scoliometer is currently the best tool available for scoliosis screening and there is moderate evidence to recommend referral with values between $5^{\circ}$ and $7^{\circ}[41]$. There is moderate evidence that scoliosis screening allows for detection and referral of patients at an earlier stage of the clinical course, and there is low evidence suggesting that scoliosis patients detected by screening are less likely to need surgery than those who did not participate to a screening protocol $[41,42]$.

\section{Conclusion}

A school screening test for biplane spinal deformities is not intended to be diagnostic but preventive. School children with positive or suspicious findings must refer to their physicians for further diagnosis and treatment.

Scoliosis/kyphosis screening is able to differentiate spines with deformities from spines without deformities and refer them for subsequent diagnostic tests in order to facilitate early intervention, thus decreasing the need for surgery through bracing.

\section{References}

1. Korovessis PG, Stamatakis MV (1996) Prediction of scoliotic cobb angle with the use of the scoliometer. Spine (Phila Pa 1976) 21: 1661-1666. [Crossref]

2. Korovessis P, Petsinis G, Papazisis Z, Baikousis A (2001) Prediction of thoracic kyphosis using the Debrunner kyphometer. J Spinal Disord 14: 67-72. [Crossref]

3. Ohlen G, Aaro S, Bylund P (1988) The sagittal configuration, and mobility of the spine in idiopathic scoliosis. Spine 13: 413-416.

4. Ohlén G, Spangfort E, Tingvall C (1989) Measurement of spinal sagittal configuration and mobility with Debrunner's kyphometer. Spine (Phila Pa 1976) 14: 580-583. [Crossref]

5. Willner S, Johnson B (1983) Thoracic kyphosis and lumbar lordosis during the growth period in children. Acta Paediatr Scand 72: 873-878. [Crossref]

6. Willner S (1981) Spinal pantograph: A non-invasive technique for describing kyphosis and lordosis in the thoraco-lumbar spine. Acta Orthop Scand 52: 525-529.

7. Mellin G (1986) Measurement of thoracolumbar posture and mobility with a Myrin inclinometer. Spine (Phila Pa 1976) 11: 759-762. [Crossref]

8. D'Osualdo F, Schierano S, Iannis M (1997) Validation of clinical measurement of kyphosis with a simple instrument, the arcometer. Spine (Phila Pa 1976) 22: 408-413. [Crossref]

9. Burwell RG, James NJ, Johnson F, Webb JK, Wilson YG (1983) Standardised trunk asymmetry scores. A study of back contour in healthy school children. J Bone Joint Surg Br 65: 452-463. [Crossref]

10. Salisbury PJ, Porter RW (1987) Measurement of lumbar sagittal mobility. A comparison of methods. Spine (Phila Pa 1976) 12: 190-193. [Crossref]

11. Debrunner HU (1972) [The Kyphometer]. Z Orthop Ihre Grenzgeb 110: 389-392. [Crossref]

12. Pascoe DD, Pascoe DE, Wang YT, Shim DM, Kim CK (1997) Influence of carrying book bags on gait cycle and posture of youths. Ergonomics 40: 631-641. [Crossref]

13. D'Osualdo F, Schierano S, Iannis M (1997) Validation of clinical measurement of kyphosis with a simple instrument, the arcometer. Spine (Phila Pa 1976) 22: 408-413. [Crossref]

14. Pheasant ST (1995) Anthropometry and the design of workspaces. In: Wilson JR, Corlett EN, eds. Evaluation of Human Work. London: Taylor and Francis, 1995.

15. Salminen JJ, Erkintalo M, Laine M, Pentti J (1995) Low back pain in the young A prospective three-year follow-up study of subjects with and without low back pain. Spine (Phila Pa 1976) 20: 2101-2107. [Crossref]

16. Korovessis P, Koureas G, Zacharatos S, Papazisis Z. Backpacks (2005) Back Pain, Sagittal Spinal Curves and Trunk Alignment in Adolescents. A Logistic and Multinomia Logistic Analysis. Spine 30: 247-255.

17. Bonagamba GH, Coelho DM, Oliveira AS (2010) Inter and intra-rater reliability of the scoliometer. Rev Bras Fisioter 14: 432-438. [Crossref]

18. Coelho DM, Bonagamba GH, Oliveira AS (2013) Scoliometer measurements of patients with idiopathic scoliosis. Braz J Phys Ther 17: 179-184. [Crossref]

19. Soucacos PN, Soucacos PK, Zacharis KC, Beris AE, Xenakis TA (1997) Schoolscreening for scoliosis. A prospective epidemiological study in northwestern and central Greece. J Bone Joint Surg Am 79: 1498-1503. [Crossref]

20. Sapkas G, Papagelopoulos PJ, Kateros K, Koundis GL, Boscainos PJ, et al. (2003) Prediction of Cobb angle in idiopathic adolescent scoliosis. Clin Orthop Relat Res. [Crossref] 
Korovessis P (2019) Evolution observation of coronal and sagittal spinal curvatures in school children with non-invasive, non-radiating methods: Scoliometer and Debrunner Kyphometer

21. Grivas TB, Vasiliadis ES, Koufopoulos G, Segos D, Triantafyllopoulos G, et al. (2006) Study of trunk asymmetry in normal children and adolescents. Scoliosis 1: 19. [Crossref]

22. Asher M, Min Lai S, Burton D, Manna B (2004) The influence of spine and trunk deformity on preoperative idiopathic scoliosis patients' health related quality of life questionnaire responses. Spine 29: 861-868.

23. Bunnell WP (2005) Selective screening for scoliosis. Clin Orthop Relat Res. [Crossref]

24. Lonstein JE, Bjorklund S, Wanninger MH, Nelson RP (1982) Voluntary school screening for scoliosis in Minnesota. J Bone Joint Surg Am 64: 481-488. [Crossref]

25. Stagnara P, de Mauroy JC, Dran G, Gonon GP, Costanzo G, et al. (1982) Reciprocal angulation of vertetebral bodies in a sagittal plane: Approach to references for evaluation of kyphosis and lordosis Spine 7: 335-42.

26. Beekman CE, Hall V (1979) Variability of scoliosis measurement from spinal roentgenograms. Phys Ther 59: 764-765. [Crossref]

27. Stoliński, L, Czaprowski D, Kozinoga M, Kotwicki T (2009) Clinical measurement of sagittal trunk curvatures: photographic angles versus rippstein plurimeter angles in healthy school children. Scoliosis 4: 053.

28. Giglio CA, Volpon JB (2007) Development and evaluation of thoracic kyphosis and lumbar lordosis during growth. Journal of Children's Orthopaedics 1: 187.

29. Amendt LE, Ause-Ellias KL, Eybers JL, Wadsworth CT, Nielsen DH, et al. (1990) Validity and reliability testing of the Scoliometer. Phys Ther 70: 108-117. [Crossref]

30. Goldberg CJ, Kaliszer M, Moore DP, Fogarty EE, Dowling FE (2001) Surface topography, Cobb angles, and cosmetic change in scoliosis. Spine (Phila Pa 1976) 26: E55-63. [Crossref]

31. Newton PO, Wenger DR (2006) Idiopathic scoliosis. Lovell and Winter's Pediatric Orthopaedics Lippincott Williams \& Wilkins, Philadelphia Morrissy, RT, Weinstein, SL, pp: 693.
32. Goldberg CJ, Moore DP, Fogarty EE, Dowling FE (2000) The relation between minor asymmetry and early Idiopathic Scoliosis. In Research into Spinal Deformities 3 Edited by: Tanguy A, Peuchot B. Amsterdam, Berlin, Oxford, Tokyo, Washington DC: IOS Press; 2000: 17-19.

33. Ingelmark BE, Lindstrom J (1963) Asymmetries of the lower extremities and pelvis and their relations to lumbar scoliosis. A radiographic study. Acta Morphol Neerl Scand 5: 221-234. [Crossref]

34. Papaioannou T, Stokes I, Kenwright J (1982) Scoliosis associated with limb-length inequality. J Bone Joint Surg Am 64: 59-62. [Crossref]

35. Scheller ML (1964) Uber den Einfluss der Beinverkurzung auf die Wirbelsaule. In PhD Thesis Universitat zu Koln, Cologne, West Germany.

36. Deepak AS, Ong JY, Choon DSK, Lee CK, Chiu CK, et al. (2017) The clinical effectiveness of school screening programme for idiopathic scoliosis in Malaysia. Malays Orthop J 11: 41-46. [Crossref]

37. Huang SC (1997) Cut-off point of the Scoliometer in school scoliosis screening. Spine (Phila Pa 1976) 22: 1985-1989. [Crossref]

38. Zheng Y, Dang Y, WU X, Yang Y, Reinhardt JD, et al. (2017) Epidemiological study of adolescent idiopathic scoliosis in eastern China. J Rehabil Med 49: 512-519. [Crossref]

39. Amendt LE, Ause-Ellias KL, Eybers JL, Wadsworth CT, Nielsen DH, et al. (1990) Validity and reliability testing of the Scoliometer. Phys Ther 70: 108-117. [Crossref]

40. Viviani GR, Budgell L, Dok C, Tugwell P (1984) Assessment of accuracy of the scoliosis school screening examination. Am J Public Health 74: 497-498. [Crossref]

41. Labelle, H, Richards BS, De Kleuver M, Luk KD, Wong HK, et al. (2013) Screening for adolescent idiopathic scoliosis: an information statement by the scoliosis research society international task force. Scoliosis 8: 17. [Crossref]

42. Vedantam R, Lenke LG, Keeney JA, Bridwell KH (1998) Comparison of standing sagittal spinal alignment in asymptomatic adolescents and adults. Spine 23: 211-215. [Crossref]

Copyright: (C2019 Korovessis P. This is an open-access article distributed under the terms of the Creative Commons Attribution License, which permits unrestricted use, distribution, and reproduction in any medium, provided the original author and source are credited. 